\title{
ALGUMAS DIRETRIZES SOBRE AS REPRESENTAÇÕES DE GÊNERO EM PRODUTOS INFANTIS: O USO DA LINGUAGEM GRÁFICA
}

Marcela Bezerra

marcela.bezerra@gmail.com

Resumo: O presente artigo se propôs a observar a presença de elementos da linguagem visual nos artefatos destinados às crianças, além de sugerir diretrizes norteadoras durante a construção de mensagens para meninas e meninos em suas diversas faixas etárias.

Palavras-chave: Design, representação de gênero, vestuário infantil.

Abstract: This paper proposes to observe the presence of elements of visual language in articles intended for children, and suggest guidelines for guiding the construction of messages for girls and boys in their various age groups.

Keywords: Design, gender representation, children's clothing. 


\section{INTRODUÇÃO}

A presente investigação traz um recorte de tese doutoral que analisou e propôs diretrizes metodológicas relacionadas às escolhas de gênero presentes em artefatos de design, em especial no vestuário. Durante a abordagens, foram observados elementos e formatações que compunham a mensagem visual proposta ao público mirim, sejam elas presentes em roupas, livros, brinquedos e desenhos infantis.

As escolhas e personagens foram elencados como essenciais durante a transmissão da mensagem para esse nicho de mercado, além da observação de que esses elementos trazerem consigo discursos muitas vezes propositores de ideais de gênero.

\section{REPRESENTAÇÕES GRÁFICAS DE GÊNERO INFANTIL}

Durante a concepção de produtos de design, a premissa básica para sua aceitação por parte dos usuários reside na preocupação inicial de aplicar ao projeto características inerentes ao universo do público ao qual se destina. Seja relacionado às cores, às formas, aos suportes e aos materiais nos quais estarão dispostos, observa-se que a maior relevância deve estar aplicada às escolhas adequadas durante a composição das mensagens, com o propósito de atender às suas necessidades. Em se tratando do público infantil, em especial, uma série de barreiras existe e serve de entraves durante o desenvolvimento de mensagens visuais para esse público. Seja pela dificuldade de acesso dos usuários, seja pela quantidade vasta de variáveis relacionadas à idade, ao gênero, ao universo onde está inserida a criança, diversos fatores contracenam ao mesmo tempo, tornando o trabalho de definição de indicações para o público mirim ainda mais árduo.

Hoje é possível localizar algumas investigações científicas que observam temáticas que se debruçam em pesquisar as crianças e o que as envolve. No entanto, especificamente ao relacionar-se com escolhas presentes em elementos da linguagem gráfica destinada às crianças ainda existe uma grande lacuna de investigações. Ao observar-se em especial a criança do século 21 , cabe registrar que eles vivem em uma sociedade rodeada de referências visuais e, nesse caso, desenvolver produtos para esse público-alvo representa criar algo que a provoque e encante visualmente (MELO, 2001, p. 24).

Neste trabalho, em especial, em vários momentos são feitas leituras de preferências e aplicações das mensagens visuais destinadas a esse público, pontuando os elementos de design indicados para livros infantis, ilustrações, desenhos animados e jogos na tentativa de criar um aparato passível de ser aplicado na adoção de técnicas visuais inseridas no vestuário infantil. Para tanto, alguns autores de áreas correlatas continuarão a ser pesquisados e apontados como referência, na tentativa de dar início a um pensamento alicerçado da linguagem visual adequada para as crianças a partir de sua faixa etária.

\subsection{Personagens presentes nos elementos compositivos da linguagem visual}

Dentre os diversos elementos que compõem a mensagem visual destinada ao público infantil como cor, forma, texto, ilustrações e personagens, comumente é vista a associação de dois ou mais atributos como forma de garantir a apreensão e 
compreensão da comunicação proposta para as crianças. A união de formas, cores e suportes possibilita uma maior interação entre sujeito e produto, o que permite que o discurso seja enriquecido, partindo de apelos mais convincentes. Ilustrações e personagens hoje tem presença garantida nos produtos destinados às crianças, certamente por relacionarem mais intimamente com o imaginário infantil.

Montigneaux afirma que:

[...] os personagens imaginários são uma parte absorvente do universo da criança. Tem por origem domínios extremamente diversos. Saem das histórias contadas pelos pais e pelos avós, dos filmes, dos desenhos animados, do universo dos desenhos em quadrinhos ou dos produtos de grande consumo (MONTIGNEAUX, 2003, p. 104).

As crianças, segundo o autor, compreendem o personagem como se fosse uma pessoa real, que faz parte de sua vida cotidianamente, estabelecendo relações sociais estreitas e amigáveis. Montigneaux (2003) apresenta a partir de pesquisas afins que fatores como descrição dos personagens, definições de comportamento e perfis atitudinais são extremamente percebidos pelas crianças ao relacionar-se com personagens. Para a Reason Why Kids, foram observadas as principais razões para identificação imediata das crianças em relação aos personagens.

O personagem é visto e apreciado pela criança por meio de várias dimensões:

- o personagem é engraçado, simpático (com efeito, é associado, muitas vezes, aos jogos e às brincadeiras). A dimensão lúdica é a mais importante;

- o personagem acompanha a criança durante todo o dia. É uma companhia fiel;

- o personagem representa um universo imaginário. Ele traz para a criança uma dimensão mágica através de seus poderes ou suas capacidades físicas ou intelectuais excepcionais que permitem à criança a fuga do seu cotidiano (MONTIGNEAUX, 2003, p. 105 - grifo nosso).

Ainda segundo o autor, em especial as crianças de menor idade são mais suscetíveis ao poder de atração dos personagens de marca e em média a partir dos seis anos de idade, os consumidores já começam a perceber o papel de sedução que os personagens desempenham nos produtos de grande consumo. Nos quadrinhos, por sua vez, os personagens têm grande poder de atração das crianças pois o leitor tende a interpretar o que lê com convicção e dramaticidade, configurando-o a partir de sua interpretação (LOVRETO, 1995, p. 1). Ainda segundo o autor, o que gera esse fascínio das crianças é o encanto que o desenho desperta. Depois de criar uma imagem sobre o papel, os leitores identificam-se com os personagens e tem vontade de ler suas aventuras. "O impacto visual é sempre a mola que move a vontade de ler (LOVRETO, 1995, p. 2).

Montigneaux propõe que existem conceitos que fazem com que os personagens sejam melhores aceitos pelo público mirim. Para ele, características presentes nos personagens são responsáveis por causar interação ou rejeição por partes do seu público-alvo. As características físicas e os traços de personalidade dos personagens são os atributos com maior destaque durante o envio da mensagem para o público infantil. Para ele, "a criança admira menos os atributos físicos 'brutos' dos personagens do que aqueles que denotam uma certa 'inteligência' do corpo (MONTIGNEAUX, 2003, p.107)". 
Já no que diz respeito aos traços de personalidade o autor aponta que as crianças se dão conta de poucos traços de personalidade. Para os pequenos, coragem, bondade e gentileza caracteriza em grande parte das vezes o herói que eles idealizam. Embora existam essas características com grande peso de informações durante a emissão de mensagens ao público infantil, Montigneaux acrescenta que:

[...] essa representação apenas não é suficiente para motivar o interesse da criança [...] O personagem é um modelo inspiracional que deve ajudar, conduzir a criança ao status de adulto. É pelo fato de o personagem propor à criança um modelo de comportamento e um projeto que o processo de identificação poderá ocorrer (MONTIGNEAUX, 2003, p. 109).

Pelo exposto, é possível notar a importância que um personagem tem enquanto elemento gráfico transmissor de informações para o público infantil. Talvez por esse público ainda não ter domínio de expressão, o personagem e seu universo mágico sejam capazes de representá-lo no mundo real. No vestuário infantil, universo investigado no presente estudo, comumente são aplicados personagens para se dirigirem ao público mirim, utilizando-se de toda sua narrativa para estabelecer um elo de ligação entre aquele produto de moda e o pequeno usuário (figura 01).

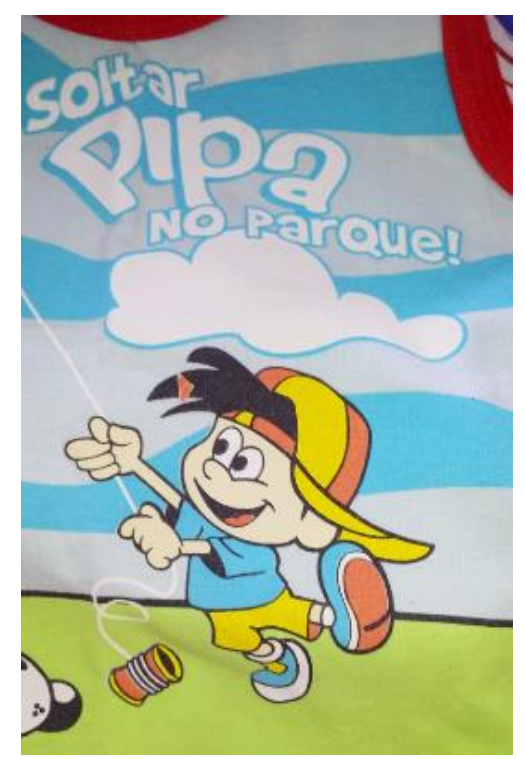

Figura 1. Personagem como centro da ilustração na roupa infantil.

Fonte: Arquivo pessoal (2014).

Para tanto, características tanto do personagem, quanto do público-alvo destacamse e validam sua aplicação no vestuário.

\subsection{Casos análogos: desenhos animados, jogos, propagandas televisivas e livros infantis}

Ao estabelecer uma relação entre a criança e o livro infantil, Romani (2011, p. 19) afirma que "quando a criança lê um livro, ela aprende não com o significado das palavras, mas incorpora os valores estéticos". Para a autora, o desenho da organização nas páginas que integram um livro infantil importa não apenas pela ilustração presente no volume, mas especialmente na maneira de disponibilizar as informações gráficas e 
como o leitor recebe esse estímulo. Para Lago (2008) apud Romani:

O leitor exerce um importante papel no livro-objeto, ele participa da obra. A ação de virar as páginas, a escolha do movimento das folhas, permite ao leitor a mudança no ângulo de visão e leitura exclusiva da obra (LAGO, 2008 apud ROMANI, 2011, p. 20).

Inserir o usuário na participação e decisão das ações de leitura certamente é reflexo das escolhas feitas ao longo do desenvolvimento do produto destinado ao público infantil, seja isso a partir dos elementos presentes no livro objeto, nos personagens, cores e formas que ele encontra durante o contato com o produto de design (figura 2).

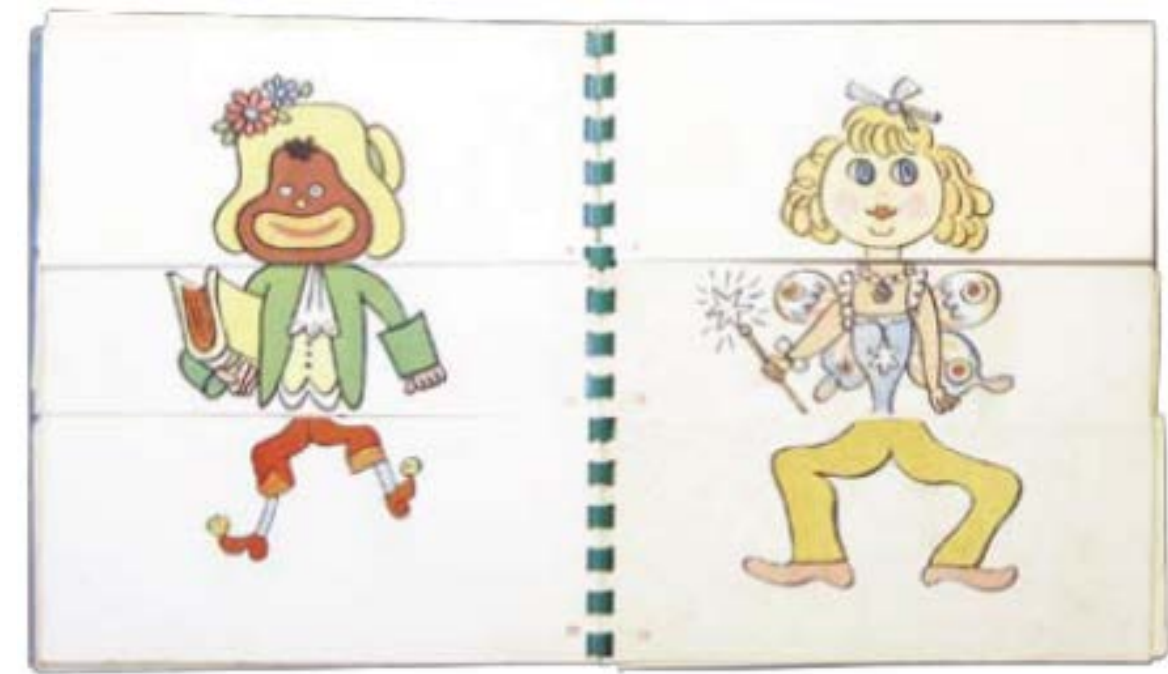

Figura 2. Exemplo de ilustração em livro infantil. Fonte: Ilustração em livro-objeto. Romani, 2011, p. 20.

Para Perrot (1987) apud Romani:

O uso de cores ilustrações e o trabalho com a forma do objeto permitem à criança a leitura da imagem como um pequeno explorador, ampliando a perspectiva do imaginário. A criança se insere num mundo mágico que a motiva a abrir e fechar o livro repetidas vezes, num processo de releitura e novas descobertas (PERROT,1987 apud ROMANI, 2011, p.21).

Essa abordagem aponta a criança como receptor da mensagem visual e que essa linguagem a ela destinada estimula-a e motiva-a a consumir o conteúdo sugerido pelo autor. Em especial pelos desdobramentos para o público infantil, Martins (2001, p. 13) apud Fernandes (2005) aponta que o contato com elementos adequados a exemplo de texto/imagem e a familiaridade com material de beleza plástica, certamente resultará em benefícios para a criança, que possivelmente tornar-se-á leitora competente e crítica futuramente.

No que diz respeito a produtos desenvolvidos para o público infantil, em especial durante a criação de livros, Christiana Costa apud Romani D.(2010, p.24) orienta que algumas recomendações têm essencial relevância na produção eficaz para 
os pequenos (Tabela 1$)$.

\begin{tabular}{|l|l|}
\hline Até os três anos & $\begin{array}{l}\text { Recomenda-se utilizar livros com gravuras de bichinhos, brinquedos } \\
\text { e animais com características humanas. }\end{array}$ \\
\hline $\begin{array}{l}\text { Entre três e seis } \\
\text { anos }\end{array}$ & $\begin{array}{l}\text { Opte por histórias com muita fantasia. Com fatos inesperados e } \\
\text { repetitivos (exemplo: aqueles que têm como recurso os lenga- } \\
\text { lengas) e cujos personagens são crianças ou animais. }\end{array}$ \\
\hline Sete anos & $\begin{array}{l}\text { São indicados os contos de fadas e histórias sobre o ambiente onde } \\
\text { estão inseridas. Fábulas também podem ser contadas a partir dessa } \\
\text { idade. }\end{array}$ \\
\hline Oito anos & $\begin{array}{l}\text { A dica é optar por histórias que utilizam a fantasia de forma mais } \\
\text { elaborada. Histórias vinculadas à realidade. }\end{array}$ \\
\hline Nove anos & $\begin{array}{l}\text { São indicadas as aventuras em ambientes longínquos ou histórias } \\
\text { que se passem em outros planetas. As crianças também vão gostar } \\
\text { de aventuras e narrativas de viagens. }\end{array}$ \\
\hline Dez a doze anos & Utilize narrativas de viagens, explorações, invenções e mitos. \\
\hline
\end{tabular}

Tabela 1. Atribuições e características por idades e compreensões das crianças.

Fonte: Quadro extraído do Especial Literatura Infantil da Revista Continente. (ROMANI D., 2010, p. 24).

O uso de elementos condicionados à idade e ao desenvolvimento da criança em dado momento aparece como alternativa eficaz para a criação de produtos que despertem o interesse dos pequenos.

Em outro exemplo, ao estabelecer que a televisão represente um grande veículo transmissor de informações para as crianças na atualidade e responsável por muitas escolhas, definição de valores e conhecimentos, Esperança e Dias $(2010$, p. 1) pontuam que, no que diz respeito ao desenho animado infantil, já existem questões relacionadas às preferências de gênero que são exemplificadas pelas características gráficas e de valores presentes nos desenhos (Figuras 3 e 4). Para as autoras, tais desenhos servem até como embasamento de referenciação indicando como serem meninas e meninos.
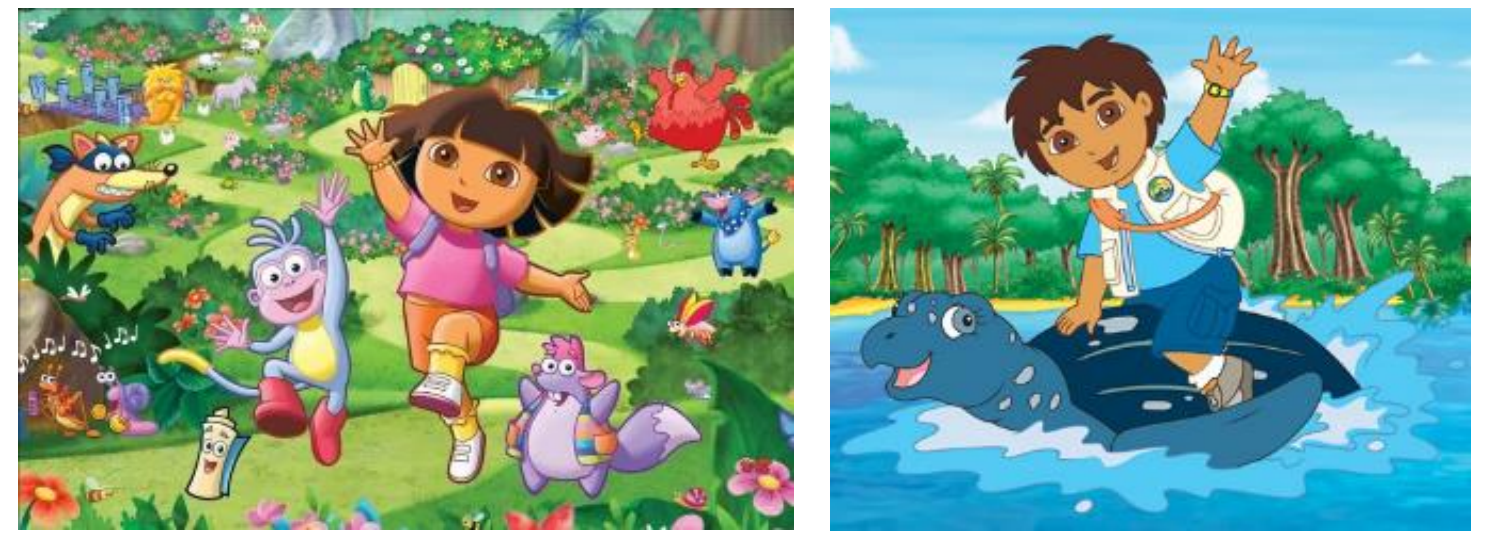

Figura 3. Exemplo de desenhos infantis de meninas (Dora aventureira com cenário florido) e Figura 4. Ex. meninos (Diego Go atividades radicais, como aventuras na floresta). Fonte: Arquivo pessoal (2014)

Em recente pesquisa, ao observar em especial as escolhas relacionadas ao gênero dos pequenos telespectadores, Esperança e Dias (op cit, p. 3) atribuíram que os personagens aliados a cores, formas e atitudes eram responsáveis pela aceitação - e 
negação - das crianças, sendo elas meninas e meninos. As ênfases de relacionamentos e atos heróicos eram características vistas pelas crianças como extremamente opostos, despertando interesse pelas crianças que faziam parte do grupo em questão. Fica claro aqui que referências de cada um dos grupos - meninas e meninos - ao fazer parte dos enredos das histórias eram capazes de despertar interesses. Estereótipos de gênero como brincadeiras de casinha para meninas e de super-heróis para meninos são comumente usados nos desenhos como forma de associação imediata pelos públicos a que se destinam.

Do mesmo modo que ao citar as referências de gênero infantil, alterando agora o suporte de observação, é possível notar que as propagandas televisivas direcionadas às crianças também merecem destaque em uma investigação atual. Guizzo (2005, p. 48) defende que na chegada da televisão ao Brasil, em meados de 1950, o público infantil não era alvo ainda da mídia, visto que a grade de programação era destinada ao público adulto. A autora afirma que até a década de 1960 os espaços veiculados para as crianças eram representados pelos clássicos da literatura universal, a exemplo de Chapeuzinho Vermelho, Cinderela, entre outros. Apenas após esse período as crianças passam de espectadoras para protagonistas de alguns quadros da programação.

Com esse novo e promissor nicho no mercado, comerciais passaram a ser produzidos e veiculados nos intervalos dos programas mirins, destacando atitudes e brincadeiras vivenciadas pelas crianças. Produtos alimentícios, jogos, brinquedos, roupas e sapatos passaram a ser divulgados para esse público considerando seu universo, com características próprias com o propósito de uma audiência quase imediata. Assim como proposto por Esperança e Dias (2010), mais uma vez, segundo Guizzo (2005, p. 54), as escolhas durante a produção das peças televisivas se distinguem em função das ações praticadas por meninas e meninos (Figuras 4 e 5).
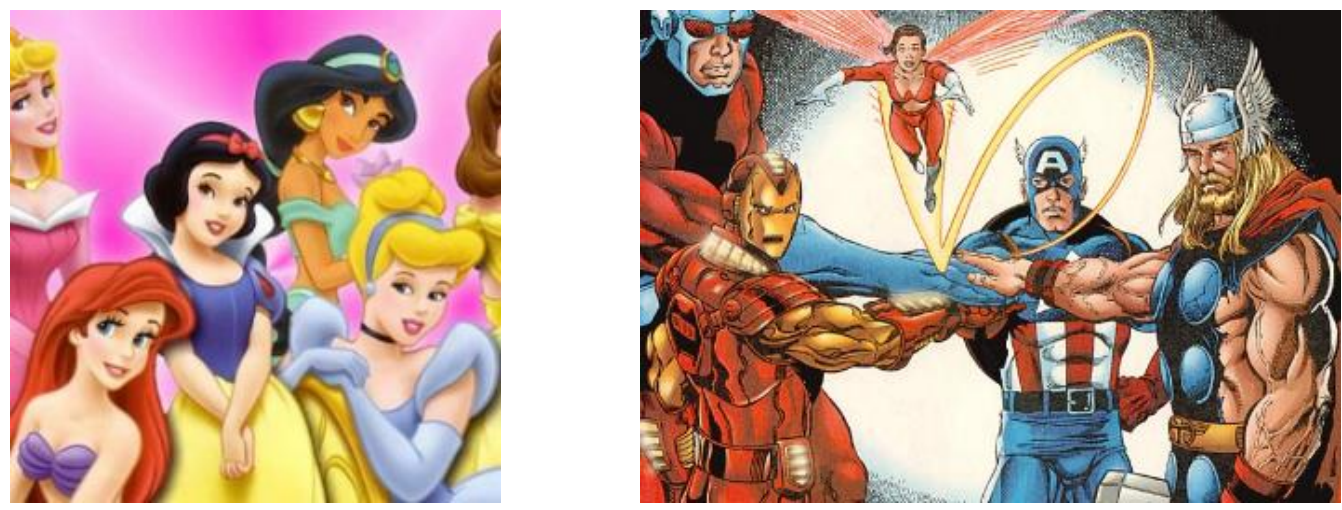

Figura 4. Propagandas infantis para meninas e

Figura 5. Propagandas infantis destinadas aos meninos.

Fonte: Arquivo pessoal (2014)

Ainda segundo Felipe (1999) apud Guizzo (2010, p. 54), "de um modo geral, as ações desenvolvidas nas propagandas protagonizadas pelos meninos envolvem situações de aventura, ação, perigo e agilidade. Entretanto, as protagonizadas por meninas dizem respeito especialmente ao cultivo da beleza e ao culto à maternidade". Para a autora, ainda que as temáticas adaptem-se ao contexto, em algum momento com frequência aparecem cristalizadas em exemplos tradicionais de gênero. 
Além das escolhas relacionadas ao gênero, também são apontados nas propagandas televisivas elementos que constituem a mensagem visual. Características como cores, movimentos, imagens, ações e até falas dos personagens tendem a reproduzir rotinas e representações sobre os modos de ser meninas e meninos (GUIZZO, 2010). Ao longo do texto, a autora aborda personagens e qualidades que se relacionam em sua maioria a um dos gêneros: menina ou menino. A Barbie retrata um passeio pelos contos de fadas, pelas histórias felizes, atualiza-se com a realidade retratando as bonecas profissionais, posicionando a menina de forma feminista, que pode tudo. As Garotas Superpoderosas Lindinha, Florzinha e Docinho misturam "açúcar e tudo o que há de bom" e também retratam a delicadeza e interliga às meninas. Os personagens associados aos meninos apresentam características bem diferentes das meninas. Os carrinhos da série Hot Wheels divergem do cenário feminino ao executar suas manobras de forma ágil, apelando para violência e virilidade, a partir de comerciais narrados com voz grave e firme. Outro personagem citado por Guizzo (2010) é o Johnny Bravo, descrito como homem alto, musculoso e de grande aceitação entre as mulheres no seu desenho por conta da sua vaidade e do seu sucesso com golpes de karatê.

Para a autora, as propagandas são destinadas a um público específico e, portanto, deve dirigir-se a esse público da forma que ele deseja ser retratado. Durante seu pensamento, Guizzo (2010) pontua que essas representações aparecem de forma quase invisível e ainda assim tendem a regular as determinações da identidade de gênero.

Quanto ao desenvolvimento nacional de produtos áudio visuais para o público infantil é possível apontar um exemplo de peso na última década, representado pelo fenômeno de vendas e de licenciados da turma da Galinha Pintadinha. Surgido em 2006, o personagem tem seu faturamento estimado em mais de $\mathrm{R} \$ 20$ milhões (CORONATO \& CISCATI, 2013). O personagem interpreta cantigas populares de domínio público e encanta crianças em todo o País com seus cd's, roupas, brinquedos, jogos e mais uma infinidade de produtos licenciados. Embora aborde músicas de domínio popular e aparentemente não apresentem relações de gênero nas composições, algumas canções podem ser vistas à luz de uma ou outra afirmação relacionada às ações tidas como masculinas ou femininas (figuras 6 e 7), o que pode ser visto como uma forma de caracterizar algum padrão estereotipado no entendimento das crianças.
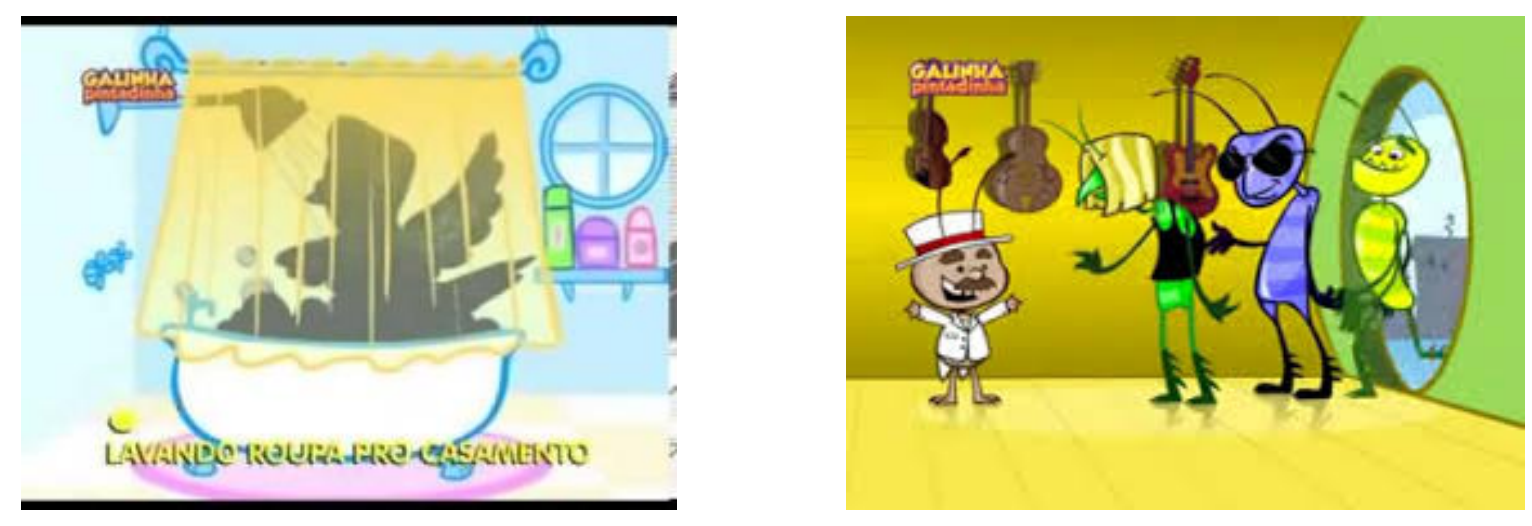

Figura 6. Cenas de vídeos da Galinha Pintadinha ao sugerir atitudes femininas e

Figura 7. Cenas de vídeos da Galinha Pintadinha ao sugerir atitudes masculinas. Fonte: Arquivo pessoal (2014). 
Além de livros, desenhos e propagandas destinadas ao público infantil, faz-se necessário observar um produto de design costumeiramente presente no cenário das crianças na atualidade: os jogos destinados ao público mirim. Assim como os produtos ou atividades já observadas, os jogos são agrupados muitas vezes pelas habilidades e desenvoltura que podem ser atribuídas às meninas ou aos meninos. Flores (2013) pontua em sua investigação características tanto visuais, quanto estruturais na apresentação de jogos para meninas e meninos. Para a autora, inicialmente já existe uma clara diferenciação dentre os jogos pelos próprios nomes que, ou estão atrelados aos personagens e heróis (MaxSteel, Barbie, Meninas Superpoderosas, Monstros S.A.) ou destinam-se ao público a partir da ação que vai ser executada ao longo do jogo (derrotar um exército, ganhar uma corrida, cuidar de um bebê, preparar uma receita). Para Flores:

[...] As informações encontradas na apresentação do site para meninos, por exemplo, sugerem que os usuários deste espaço são mais espertos, pois abordam questões acerca da tecnologia e dos desafios que os jogos proporcionam. Indiretamente, enfatiza que os meninos ficarão mais inteligentes, com mais habilidades e consequentemente conseguirão resolver os desafios propostos nos jogos. No entanto, estes termos não constam na apresentação das meninas, já que a sua abordagem direciona para a composição do site e a variedade de programas disponíveis, como afirmar que com jogos as meninas poderão ter vários desenhos para colorir, papéis de parede para baixar e desenhos animados, trailers e vídeos para assistir e se divertir (FLORES, 2013, p. 27, grifo nosso).

A autora também observa questões gráficas presentes nos jogos como cenários e cores apresentados para meninas e meninos (figuras 8 e 9). Nos jogos observados para meninas foram observados jogos de habilidades ou que tinham a moda como centro das atividades, dessa forma Flores (2013) pontua a presença de características comuns nos jogos, como:

- Elementos: cenários com flores, organização, adornos nos instrumentos;

- Cores: rosa, roxa e vermelho como cores principais, além do verde e azul para fazer os contrastes;

- Atividades: tarefas domésticas ou profissões femininas (cozinheira, professora, líder de torcida).

Em se tratando do universo masculino, Flores (2013) mais uma vez destaca as habilidades que mais se destacam dentre os jogos de meninos e aponta que as temáticas mais comuns seriam jogos de luta, tiro ou corrida. Dentre eles, foi possível observar elementos inerentes aos jogos destinados aos meninos:

- Elementos: cenários com ambiente agressivo, sério e radical.

- Cores: fortes ou escuras, em especial uso do vermelho;

- Atividades: atividades de luta, habilidades, destreza e que estimulam o raciocínio. 

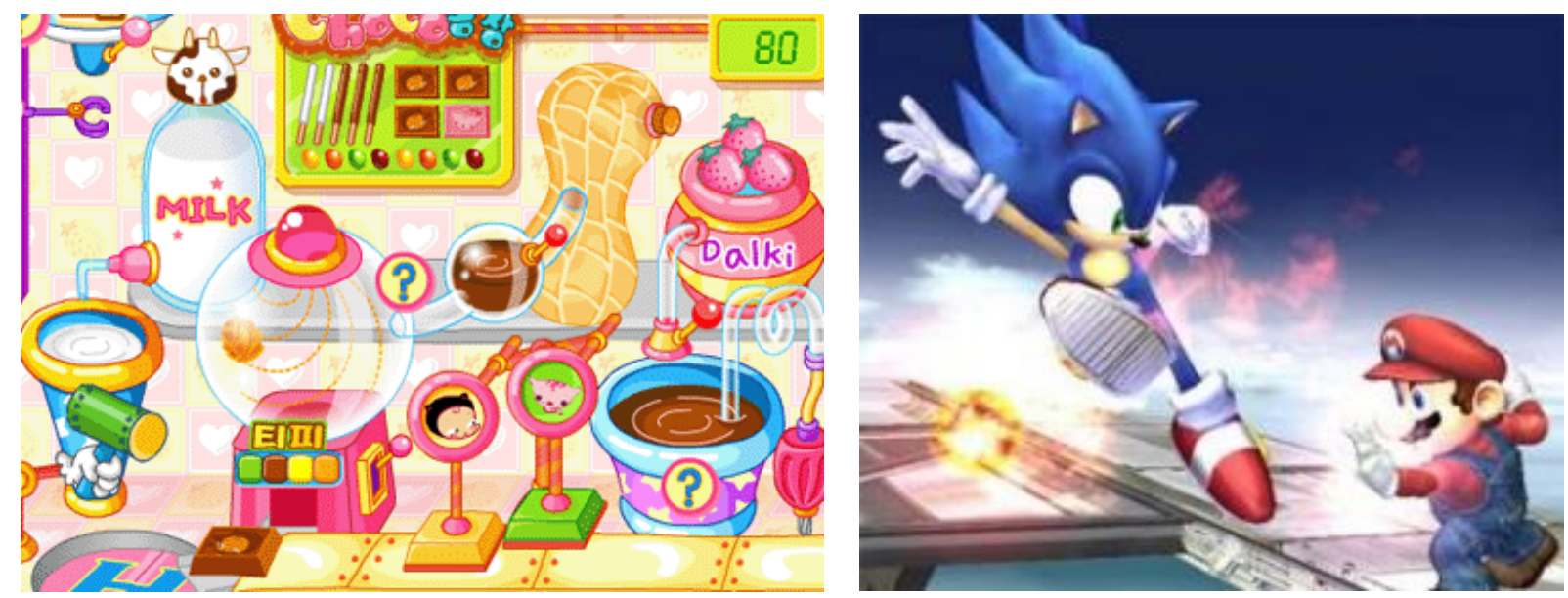

Figura 8. Exemplo de jogos infantis com atividades para meninas e

Figura 9. Exemplo de jogos infantis com atividades para meninos.

Fonte: Arquivo pessoal (2014).

Seja qual for o suporte ou objeto de design, os elementos compositivos devem estar alinhados com os públicos a que se destinam, sejam meninas ou meninos. Cores, formas, texturas e mensagens visuais devem ser utilizadas para agregar valor aos produtos, ao considerar as necessidades e preferências dos usuários, sem necessariamente induzir alguma leitura.

\section{CONCLUSÕES}

A partir do que foi tratado pelos autores até aqui, independentemente da categoria observada - roupas, livros, desenhos, jogos e propagandas voltadas para o público infantil - as características presentes nos produtos e os contextos apontados como mediadores da relação de identidade de gênero entre meninas e meninos permanece quase inalterado. Cores, formas e habilidades na maioria das categorias são retratadas de maneira semelhante, posicionando elementos pontuais para uso durante o desenvolvimento infantil.

A inclusão dessa temática na investigação importa pela relevância que o tema tem ao longo do desenvolvimento de produtos destinados ao público infantil. De posse das informações acerca dos elementos compositivos do design, as observações sobre os artefatos se fazem mais coerentes, ao passo que as propostas a serem desenvolvidas levarão em consideração os conceitos e indicações de cada elemento presente no objeto projetado.

Posto isto, além da linguagem visual, outros valores também necessitam ser observados, em especial no vestuário, de modo que a aplicação seja eficaz também nos produtos de vestuário infantil. Para tanto, considera-se como relevantes, serem observados a posteriori como complemento, questões que dizem respeito às roupas destinadas ao público mirim e suas características, como forma de observar a presente investigação aplicada. 


\section{REFERÊNCIAS}

CORONATO, Marcos; CISCATI, Rafael. Como os criadores da Galinha Pintadinha ficaram milionários: $O$ estilo próprio dos dois sócios que enriqueceram com a febre da Galinha Pintadinha para cuidar dos negócios e do dinheiro. Revista Época, São Paulo, p.00-01, 11 dez. 2013. Semanal. Disponível em: <http://epoca.globo.com/vida/vida-util/ carreira/noticia/2013/10/como-os-criadores-da-bgalinha-pintadinhab-ficarammilionarios.html>. Acesso em: 10 fev. 2014.

ESPERANÇA, Joice Araújo; DIAS, Cleuza Sobral. Meninos versus meninas: representações de gênero em desenhos animados e seriados televisivos sob olhares infantis. Revista do Centro de Educação, Santa Maria, v. 35, n. 3, p.533-546, set./dez. 2010. Septiembre-diciembre. Disponível em: <http://www.redalyc.org/articulo.oa? id=117116968013>. Acesso em: 12 out. 2013.

FLORES, Cristiane Luiza Abbud. Relações de gênero nos sites de jogos infantis: entre a beleza e a força. 2013. 49 f. TCC (Graduação) - Curso de Licenciatura em Pedagogia, Departamento de Faculdade de Educação, Universidade Federal do Rio Grande do Sul, Porto Alegre, 2013.

GUIZZO, Bianca Salazar. Identidades de gênero e propagandas televisivas: um estudo no contexto da educação infantil. 2005. 157 f. Dissertação (Mestrado) - Curso de Educação, Universidade Federal do Rio Grande do Sul, Porto Alegre, 2005.

LOVRETO, José Alberto. Quadrinhos: A linguagem completa. Comunicação e Educação, São Paulo, v. 2, p.1-8, 05 nov. 2013. Jan/abr.

MARTINS, Lúcia Maria Cruz. A TRANSVERSALIDADE DA LITERATURA INFANTIL EM CONTEXTO PRÉ-ESCOLAR. 2011. 144 f. Dissertação (Mestrado) - Curso de Educação, Departamento de Escola Superior de Educação de Portalegre, Instituto Politécnico de Portalegre, Porto Alegre, 2011.

MONTIGNEAUX, Nicolas. Público-alvo: crianças: a força do personagem e do marketing para falar com o consumidor infantil. Rio de Janeiro: Editora Campus, 2003. $269 \mathrm{p}$.

ROMANI, Danielle. Literatura Infantil. Revista Continente, Recife, v. 111, p.20-31, Março, 2010. Mensal

ROMANI, Elizabeth. Design do livro-objeto infantil. 2011. 144 f. Dissertação (Mestrado) - Curso de Arquitetura e Urbanismo, Departamento de Faculdade de Arquitetura e Urbanismo, Universidade de São Paulo, São Paulo, 2011. 